\title{
Relationship between Elasticity and Contraction Force in Conducting Polymer; Polyaniline Softactuator
}

\author{
Keiichi Kaneto*, Hiroki Takahashi, Fumito Hata and Sadahito Uto \\ Department of Biomedical Engineering, Osaka Institute of Technology, \\ 5-16-1, Ohmiya, Asahi-ku, Osaka, 535-8585 Japan \\ *Corresponding author: e-mail:keiichi.kaneto@oit.ac.jp
}

\begin{abstract}
Conducting polymers expand and contract by electrochemical oxidation and reduction, respectively. The electrochemical deformation (strain), which is caused by insertion and exclusion of anion, demonstrates artificial muscles (softactuator). The magnitude of strain depends on bulkiness (size) and number of inserted anions. The contraction force (stress) is associated with the elasticity of polymers. In this study the electrochemical strain has been measured as a function of tensile loads to elucidate the mechanism of electrochemical stress in conducting polymer, polyaniline films in various acid electrolytes. The results of electrochemical stress are compared with the elasticities of the films obtained by static stress-strain curves. The electrochemical stress is qualitatively discussed based on the elasticity of the films and anion size of various acid electrolytes.
\end{abstract}

Key words: conducting polymer, polyaniline, softactuator, contraction force, elasticity

\section{Introduction}

Robot arms are precisely and quickly accessed by motors to programed positions in manufacturing factories. However, the movement of robots is noisy and not human friendly. A part of motor drive robots is desirable to be replaced with artificial muscles or softactuators, especially for welfare robots in the future.

Recently, electroactive polymers are studied for artificial muscles [1]. These are ionic polymer and metal composite (IPMC) [2], dielectric elastomer [3], conducting polymer [4-7], hydrogel, polymer gel [8] and carbon nanotube [9]. Among them, the conducting polymer is a potential candidate [4-7, 10], because of low operation voltage, large strain and stress, which are superior to those of skeletal muscle [10].

Conducting polymers are $\pi$-conjugate linear polymer and known to be highly conductive, when they are oxidized [11]. The oxidation can also be carried out electrochemically by applying positive voltages to the conducting polymer in an electrolyte solution [12]. This takes place by removal of electrons and insertion of the equal number of anions in electrolyte solution. The volume of anions (negative ions) is much larger than that of electron, resulting in expansion of the conducting polymers [13]. By the electrochemical reduction, the polymer contracts due to release of anions. Hence, conducting polymers deform by electrochemical oxidation and reduction, which is named as electrochemomechanical (EC) strain and utilized as artificial muscles or soft actuators [4-8].

The mechanism of deformation in conducting polymers has been studied to enhance the strain and performance of actuation for the practical use. It has been shown that the optimized EC strain of a polypyrrole (PPy) film is close to $40 \%$ [10], which can be compared with ca. $25 \%$ of skeletal muscle. The large strain was achieved by use of large anions and gel like morphology of PPy.

Electrolyte dependence of EC strain has been studied in PPy films to elucidate the mechanism of actuation [13]. It has been revealed that the magnitude of strain depends on the anion radii with solvation employed in the electrolyte solution. The solvation is a cluster of ion with solvent, in which the ion is surrounded by a certain number of solvent (water) molecules. The EC contraction force (EC stress) has also been investigated and found to be related to the elasticity of films $[14,15]$. However, few reports on the detailed origin of EC stress are found in literatures.

In this paper, the relationship of EC stress and elasticity of polyaniline (PANi) film is reported. The EC stress has been evaluated by equilibrating between the EC contraction force and tensile lords. The results indicate that the EC stress qualitatively relates to the elasticity and the anions of acid electrolytes.

\section{Experimental Procedure}

All chemicals used for preparation of PANi film were obtained from Nacalai Tesque and used without further purification. PANi film was synthesized by chemical polymerization of $0.1 \mathrm{M}$ aniline in $1 \mathrm{M} \mathrm{HCl}$ mixing with $0.3 \mathrm{M}$ ammonium peroxodisulfate in $1 \mathrm{M}$ $\mathrm{HCl}[16,17]$. The raw product of emeraldine salt (ES) was washed with $1 \mathrm{M} \mathrm{HCl}$ and pure water, followed by treatment with $1 \mathrm{M}$ aqueous ammonium to obtain emeraldine base (EB). The dry powder of EB was 
dissolved ca. $2 \%$ in $\mathrm{N}$-methylpyrrolidone, which was spread on slide glass. A shinny bronze film with thickness of $20 \sim 30 \mu \mathrm{m}$ was obtained. The EB film was cut into rectangular strips of $2 \mathrm{~mm} \times 15 \mathrm{~mm}$.

By the treatment of $\mathrm{EB}$ film with various acids like $\mathrm{HCl}, \mathrm{HBr}, \mathrm{H}_{2} \mathrm{SO}_{4}, \mathrm{HBF}_{4}$ and $\mathrm{HClO}_{4}$, ES films were obtained by immersing in $1 \mathrm{M}$ acids for an hour. The electrical conductivity $\left(\sigma_{\mathrm{el}}\right)$ of various ES films was measured by 4 probes method. The elasticity (Young's Modulus) of PANi films was measured by a handy digital force gauze HF-1 of JSV-H1000 (Nihon Keisoku Systems). The Young's Moduli were caculated from the slopes of stress-strain curves.

The EC actuation of PANi films was measured by using handmade apparatus shown in Fig.1 [13]. The PANi film was fixed between Fixer and Movement, which were immersed in electrolyte solution. The change of film length was transmitted to Reflector of Weight through Rod and Movement. A laser displacement meter detected the distance between the reflector and the meter, then, the change of film length was directly measured. The tensile load was applied by weights of reflector. The Fixer is platinum foil and working electrode (WE). Ag wire was used as a reference electrode (RE). Pt plate was served as a counter electrode (CE).

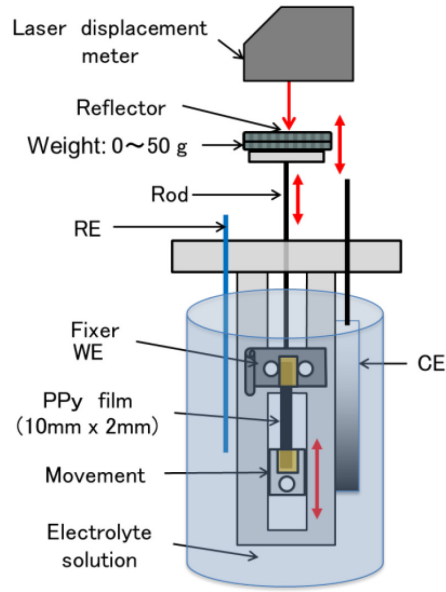

Fig.1 Apparatus for measurement of EC strain-stress in conducting polymer film.

3. Results and Discussion

3.1 Electrical conductivity and Young's Moduli

The electrical conductivities of ES films are shown in Table 1. The conductivity of EB film was less than $10^{-8} \mathrm{~S} / \mathrm{cm}$, because of the insulating properties. The conductivities of ES films are highly conductive, being more than several $\mathrm{S} / \mathrm{cm}$.

Table 1 Electrical conductivities and Young's Moduli in $\mathrm{EB}$ and various ES films

\begin{tabular}{|c|c|c|c|c|c|c|}
\hline \multirow{2}{*}{} & \multirow{2}{*}{ EB film } & \multicolumn{5}{|c|}{ ES films } \\
\cline { 3 - 7 } & & $\mathrm{HCl}$ & $\mathrm{HBr}$ & $\mathrm{H}_{2} \mathrm{SO}_{4}$ & $\mathrm{HBF}_{4}$ & $\mathrm{HClO}_{4}$ \\
\hline$\sigma_{\text {el }}(\mathrm{S} / \mathrm{cm})$ & $<10^{-8}$ & 16 & 14 & 11 & 1.4 & 1.3 \\
\hline$Y(\mathrm{GPa})$ & 0.55 & 0.61 & 0.83 & 0.65 & 0.95 & 1.05 \\
\hline
\end{tabular}

The mechanism of conductivity increase from EB to ES forms by protonation $[11,16]$ is shown in Fig.2. The ES can be reversed (deprotonated) to EB by base treatment such as ammonia. The $\oplus$ in Fig. 2 is a delocalized positive charge (polaron), which plays the role of carrier for the electrical conductivity.

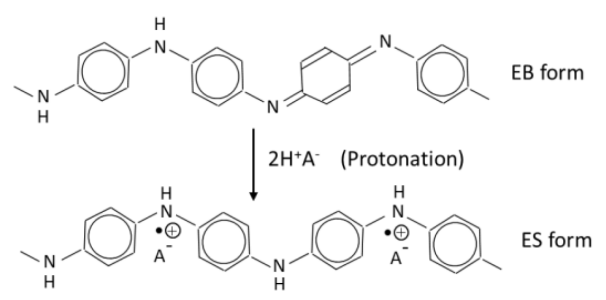

Fig.2. Conversion of $\mathrm{EB}$ to $\mathrm{ES}$ by protonation, $\mathrm{A}^{-}$is anions of $\mathrm{Cl}^{-}, \mathrm{Br}^{-}, \mathrm{SO}_{4}^{-}, \mathrm{BF}_{4}^{-}$and $\mathrm{ClO}_{4}^{-}$.

Figure 3 shows a typical force vs. elongation (stress-strain) curves in EB film with the thickness of 30 $\mu \mathrm{m}$. The stiffness increased with number of trials, possibly because of the permanent alignment of polymer chains along the tensile direction. Young's Modulus was estimated from the steepest gradient of the third run, where the trial curves were converging. The Young's Moduli $(Y)$ of PANi films were estimated by averaging the figures of a few sample strips and summarized in Table 1 .

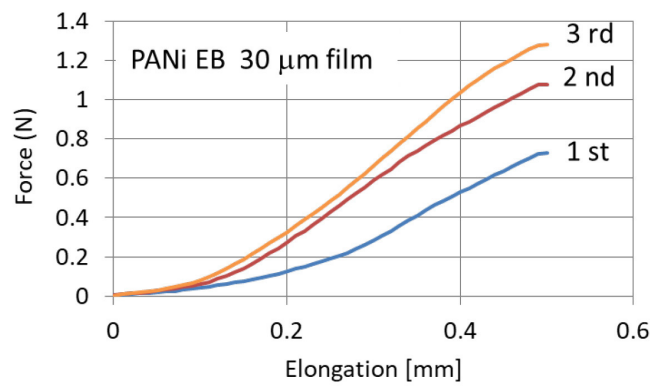

Fig. 3 Typical tensile load (force) vs. elongation curves in EB film.

As shown in Table 1, ES films are stiffer than EB film, probably because of delocalization of charged species. It is noted that the ES films with larger conductivity showed smaller Young's Moduli. Namely, ES films protonated with lager anion were lower conductivity and stiffer. The detailed mechanism for the facts is not known presently, however, the large anion may be spacing the polymer chain and playing a role of ionic crosslink between chains. Sulfonic $\left(\mathrm{H}_{2} \mathrm{SO}_{4}\right)$ acid is di-anion, and supposed to be stiffer due to ionic cross link. However, the result of Young's Modulus was small, being similar to that of $\mathrm{HCl}$.

\subsection{EC strain of ES films under tensile loads}

Curves in Fig.4 (a) depict cyclic voltammogram (CV) in $\mathrm{ES}$ film protonated with $1 \mathrm{M} \mathrm{HCl}$ for 3 cycles. The EC strain obtained by in-situ measurement is shown in Fig.4 (b). The CV curves are stable upon cycling, however, EC strain curves are shifting by cycling. The 
shifting of EC strain was caused by creeping of the film with tensile stress $(0.5 \mathrm{MPa})$ due to the weight of Rod and the Movement shown in Fig.1. For the estimation of net EC strain, the component of creeping was eliminated.

It is clearly demonstrated that the film contracted by the reduction in Fig.4 (a) and (b). That is, when the potential decreased to negative direction, as shown in Fig. 4 by curves of $1^{\text {st }}$ cycle, the EC strain of $\Delta l / l_{0}$ decreased, indicating contraction of the film. The $\Delta l$ is defined by $\Delta l=l-l_{0}$, where $l$ and $l_{0}$ are the film length during cycle and the initial length, respectively.

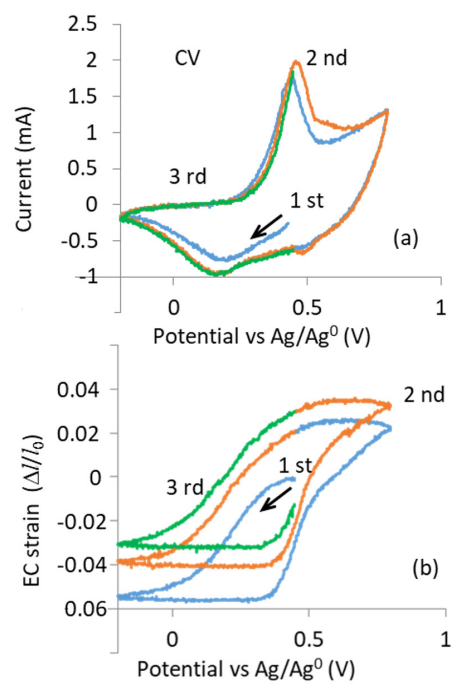

Fig.4 CV curves and EC strain of ES film electrochemically cycled in $1 \mathrm{M} \mathrm{HCl}$.

With increasing the tensile loads $(f)$, the EC strain shrunk from the maximum incremental film length $\left(\Delta l_{\mathrm{m}}\right)$ at the zero tensile loads (stress) as shown in Fig.5. The $\Delta l / l_{0}$ decreased to zero, when the contraction force was equilibrated with the tensile load at $f_{0}$ (the maximum contraction force). The relationship of $\Delta l / l_{0}$ against $f$ is empirically given by Eq. (1) for the first approximation $[14,18,19]$,

$$
\frac{\Delta l}{l_{0}}=-\frac{f}{E}+\frac{\Delta l_{m}}{l_{0}}
$$

Where, $E$ is the stress of EC contraction force per cross section of the film, and named as EC stress. At $\Delta l / l_{0}=0$, the maximum contraction stress of $f_{0}$ is obtained to be $f_{0}=E \Delta l_{m} / l_{0}$, as shown in Fig.5.

According to the Eq. (1), the best fit line is shown in Fig.5, and the EC stress was estimated from the reciprocal gradient of the line shown in Fig.5. The $E$ was also calculated from Eq. (2).

$$
E=\frac{f_{0}}{\Delta l_{m} / l_{0}} .
$$

Thus obtained EC stresses $(E)$ are summarized in Table 2, with the other parameters of Young's Moduli $(Y)$, the maximum EC strain $\left(\Delta l_{m} / l_{0}\right)$ and the maximum contraction stress $\left(f_{0}\right)$.

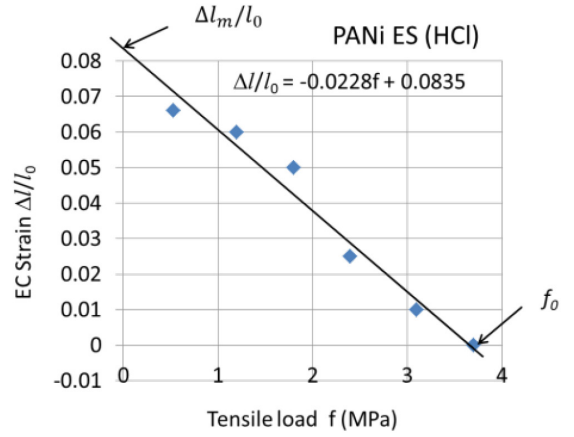

Fig.5 EC strain against tensile loads in ES film protonated with $\mathrm{HCl}$.

Table 2. Parameters of PANi ES films

\begin{tabular}{|c|c|c|c|c|}
\hline & $\begin{array}{c}Y \\
(100 \mathrm{MPa})\end{array}$ & $\begin{array}{c}E \\
(10 \mathrm{MPa})\end{array}$ & $\begin{array}{c}\Delta l_{\mathrm{m}} / l_{0} \\
(\%)\end{array}$ & $\begin{array}{c}f_{0} \\
(\mathrm{MPa})\end{array}$ \\
\hline $\mathrm{HCl}$ & 6.1 & 4.4 & 8.4 & 3.7 \\
\hline $\mathrm{HBr}$ & 8.3 & 3.2 & 6.8 & 2.2 \\
\hline $\mathrm{H}_{2} \mathrm{SO}_{4}$ & 6.5 & 1.9 & 10 & 1.9 \\
\hline $\mathrm{HBF}_{4}$ & 9.5 & 5.4 & 7.6 & 4.1 \\
\hline $\mathrm{HClO}_{4}$ & 10.5 & 4.9 & 5.2 & 2.5 \\
\hline
\end{tabular}

Parameters in Table 2 are depicted in Fig.6 with bar graph in order to compare easily. Young's Moduli $(Y)$ and $\mathrm{EC}$ stress $(E)$ in $\mathrm{ES}(\mathrm{HCl})$ and $(\mathrm{HBr})$ films are slightly smaller than those of $\mathrm{ES}\left(\mathrm{HBF}_{4}\right)$ and $\left(\mathrm{HClO}_{4}\right)$ films, except for the ES $\left(\mathrm{H}_{2} \mathrm{SO}_{4}\right)$ film. Namely, it can be said that the stiffer ES films shows qualitatively larger EC stresses $(E)$, and also larger contraction forces $\left(f_{0}\right)$, though the strain $\left(\Delta l_{m} / l_{0}\right)$ is small.

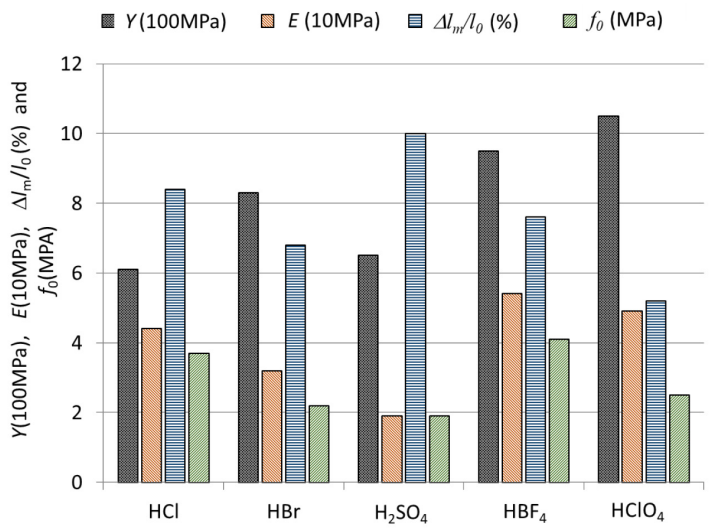

Fig.6 Comparison of Young's Moduli $(Y)$, the maximum EC strains $\left(\Delta l_{m} / l_{0}\right)$ and stresses $\left(f_{0}\right)$ in ES films prepared with various acids.

In previous papers $[15,19]$, it was reported that the Young's Modulus of the oxidized (or electrodeposited) PPy film was $0.26 \mathrm{GPa}$, and nearly equal to the EC stress. The result was thought to be reasonable. However, the present result on PANi films, the EC stress was found to be smaller than the Young's Modulus by more 
than one order of magnitude. This could be speculated to be due to the difference of film circumstance, namely, dry for Young' modulus measurement and wet condition during electrochemical actuation [20], though the details are future study.

\section{Summary}

In the present study on electrochemical actuation of PANi films, the relationship between elasticity and electrochemical stress was studied. It was found that the electrical conductivity and elasticity depend on acids used for the protonation of PANi films. The PANi films (emeraldine salt) protonated with $\mathrm{HCl}$ and $\mathrm{HBr}$ showed larger conductivity and smaller Young's Modulus compared with those of protonated with $\mathrm{HBF}_{4}$ and $\mathrm{HClO}_{4}$. The larger electrochemical (EC) strain was observed in films with smaller Young's Moduli, and the larger EC stress was obtained for the films with larger Young's Moduli. The detail mechanism for the origin of EC stress is not clear and has to be studied in future.

Acknowledgements

This work was supported by JSPS KAKENHI Grant Number; 16K06280. We also thank to Miss Y. Yamashita for assistance of experiments.

References

[1] T. Mirfakhrai, J.D.W. Madden, R.H. Baughman, Mater. Today 10, 30-38 (2007)

[2] M. Shahinpoor, Y. Bar-Cohen, J.O. Simpson, J.

Smith, Smart Mater. Struct. 7, R15-R30 (1998).

[3] R. Pelrine, R. Kornbluh, J. Joseph, R. Heydt, Q. Pei, S. Chiba, Mat. Sci. Eng., C, 11, 89-100 (2000).
[4] T.F. Otero, J.G. Martinez, J. Arias-Pardilla,

Electrochim. Acta, 84, 112-128 (2012).

5] E. Smela, O. Inganas, I. Lundstrom, J. Micromech Microeng. 3, 203-205 (1993)

[6] K. Kaneto, M. Kaneko, Y. Min, A.G. MacDiarmid, Synth. Met. 71, 2211-2212 (1995).

[7] E.W.H. Jager, N. Masurkar, N. F. Nworah, B. Gaihre, G. Alici, G.M. Spinks, Sens. Actuators, B 183, 283-289 (2013).

[8] H. Okuzaki, Y. Osada, J. Biomater. Sci., Polym. Ed. 5, 485-496 (1994)

[9] T. Sugino, K. Kyohara, I, Takeuchi K. Mukai, K. Asaka, Sens. Actuators, B 141, 179-186 (2009).

[10] S. Hara, T. Zama, W. Takashima, K. Kaneto, Smart Mater. Struct. 14, 1501-1510 (2005).

[11] A.J. Heeger, Polym. J. 17, 201-208 (1985).

[12]K. Kaneto, H. Agawa, K. Yoshino, J. Appl. Phys. 61, 1197-1205 (1987).

[13] K. kaneto, F. Hata, S. Uto, MRS Advances, in press (2018).

[14]H. Fujisue, T. Sendai, K. Yamata, W. Takashima, K. Kaneto, Bioinsp. Biomim. 2, S1-S5 (2007),

[15] S. Hara, T. Zama, W. Takashima, K. Kaneto, Polym. J. 36, 15-161 (2004).

[16]A.G. MacDiarmid, Syn. Met. 84, 119-120 (1997).

[17]W. Takashima, M. Fukui, M. Kaneko, K. Kaneto, Jpn. J. Appl. Phys. 34, 3786-3789 (1995).

[18] G.M. Spinks, V.-T Troung, Sens. Actuators. A, 119, 455-461 (2005).

[19] K. Kaneto, H. Fujisue, K. Yamato, W. Takashima, Thin Solid Films, 516, 2808-2812 (2008).

[20] K. Kaneto, T. Shinonome, K. Tominaga, W. Takashima, Jpn. J. Appl. Phys. 50, 09160 (5 pages), (2011).

(Received December 19, 2017; Accepted February 6, 2018; Published Online April 1, 2018) 